\title{
Embolization versus surgery for peptic ulcer bleeding after failed endoscopic hemostasis: a meta-analysis
}

Authors

Institutions
Moe Kyaw' ${ }^{1}$, Yee Tse' ${ }^{1}$ Daphne Ang ${ }^{2}$, Tiing Leong Ang², James Lau

${ }^{1}$ Institute of Digestive Diseases, Chinese University of Hong Kong, Shatin, Hong Kong

${ }^{2}$ Department of Gastroenterology, Changi General Hospital, Singapore received

10. September 2013 accepted after revision 4. January 2014

\section{Bibliography}

DOI http://dx.doi.org/

10.1055/s-0034-1365235

Published online: 7.3.2014

Endoscopy International Open

2014; 02: E6-E14

(c) Georg Thieme Verlag KG

Stuttgart · New York

E-ISSN 2196-9736

\section{Corresponding author}

\section{Moe Kyaw, MBBS, MSc, MRCP,}

MBA

Institute of Digestive Diseases

The Chinese University of Hong

Kong

Prince of Wales Hospital

Shatin

Hong Kong

kyawmhk@gmail.com
Background and study aims: A meta-analysis was conducted to assess the efficacy of transcatheter arterial embolization (TAE) compared with surgery in the management of patients with recurrent nonvariceal upper gastrointestinal bleeding (NVUGIB) after failure of endoscopic hemostasis. Patients and methods: Publications in English and non-English literatures (OVID, MEDLINE, and EMBASE) and abstracts from major international conferences were searched for studies comparing TAE with surgery for treatment of NVUGIB after endoscopic hemostasis failure. Outcome measures included rebleeding rate, all-cause mortality rate, and need for additional interventions to secure hemostasis.

Results: From 1234 citations, 6 retrospective comparative studies were included that involved 423 patients (TAE, 182, 56\% male; surgery, 241, $68 \%$ male). TAE patients were older (mean age, TAE 75, surgery, 68). The risk of rebleeding was significantly higher in TAE patients compared

\section{Introduction \\ $\nabla$}

Peptic ulcer disease is the leading cause of nonvariceal upper gastrointestinal bleeding (NVUGIB) with endoscopic treatment being the firstline modality [1]. After the index endoscopy, rebleeding occurs in up to $20 \%$ of cases, with a mortality rate of $10 \%$ [2]. Recurrent bleeding after endoscopic therapy is associated with significant mortality, with a higher risk in older populations and those with multiple co-morbidities [3]. Surgery has been used as a rescue therapy after failed endoscopic hemostasis, but the mortality rate can be high as $40 \%[4,5]$. In such high risk patient groups transcatheter arterial embolization (TAE) has been proposed as an alternative to surgery in those patients where endoscopic hemostasis was not successful [6]. Since the early report by Rösch et al. over 40 years ago, the use of selective arterial embolization as a method of control- with surgically treated patients (relative risk [RR] $1.82,95 \%$ confidence interval [95\%CI] $1.23-2.67$ ), with no statistically significant heterogeneity among the included studies $\left(P=0.66, I^{2}=0.0 \%\right)$. After sensitivity analysis excluding studies with a large age difference between the two groups, a higher risk of bleeding remained in the TAE group (RR 2.64, 95\%CI] 1.48-4.71). No significant difference in mortality (RR $0.87,95 \% \mathrm{CI} 0.59-1.29$ ) or requirement for additional interventions ( $R R$ $1.67,95 \%$ CI $0.75-3.70$ ) was shown between the two groups.

Conclusion: A higher rebleeding rate was observed after TAE, suggesting surgery more definitively secured hemostasis, with no significant difference in mortality rate or requirement of additional interventions. The TAE patients were older and in poorer health, thus future randomized studies are needed for accurate comparison of the two modalities.

ling acute gastrointestinal bleeding has increased [7].

Currently there are no guidelines on the use of TAE in cases of recurrent bleeding in NVUGIB emergencies, and the choice of TAE or surgery is made at the discretion of the attending clinician. The aim of this study was to assess the evidence related to benefits of TAE compared with surgery in the management of patients with recurrent NVUGIB after failure of endoscopic hemostatsis. The primary objective was to determine the rebleeding rate of TAE compared with surgery. The secondary objectives were to determine the allcause mortality rate of TAE compared with surgery, and the requirement of additional interventions to secure hemostasis. 


\section{Patients and methods}

$\nabla$

\section{Search methods}

Computerized medical literature searches were initiated through databases from September 1950 up to September 2013 using OVID MEDLINE (1950 to September 2013), EMBASE (1980 - September 2013), the Cochrane Central Register of Controlled Trials and systematic reviews (1991 to the 3 rd quarter of 2013), Database of Abstracts of Reviews of Effects (1991 to the 3 rd quarter of 2013). All abstracts from Digestive Disease Week (DDW) and United European Gastroeneterology Week (UEGW) were searched, including clinical trials databases (http://www.clinicaltrials.gov). To achieve maximum sensitivity of the search strategy and to identify all studies comparing TAE and surgery, a combination of text and MeSH terms were used: "embolization, therapeutic", "gastrointestinal hemorrhage". The reference lists of all retrieved articles were reviewed for further identification of potentially relevant studies. In addition, experts in the field were contacted.

\section{Selection criteria}

All randomized controlled trials, case-control or cohort studies were included if they met the following criteria: (i) TAE compared with surgery results; (ii) at least two of the following outcomes reported: rebleeding rate, mortality rate, further intervention to secure hemostasis. Both full articles and abstracts were included. Both English language and non-English language publications were included; local scientists and clinicians fluent in the original language of the article were contacted for translation.

Studies were excluded which did not include a comparative group that contained surgery as a form of intervention, because a meta-analysis is not appropriate if the studies did not have a comparative arm. When centers had published duplicate trials with accumulating numbers of patients or increased lengths of follow-up, only the most recent or complete reports were included for qualitative appraisal and meta-analysis.

\section{Data collection and analysis}

To avoid discordant evaluation and extractor bias, two analysts performed two separate readings (M. H. K and Y. K. T). Discrepancies between the two investigators were resolved by discussion and consensus with a senior investigator (J. Y. W. L). The following data were extracted: year of publication, study location, number of patients, patient demographics, techniques of TAE and related complications, rebleeding rate, mortality rate, and additional interventions required to secure hemostasis.

\section{Assessment of study quality and risk of bias}

The Newcastle-Ottawa scale (NOS) proposed by the Cochrane Collaboration was used for assessing the quality of the nonrandomized studies [8]. It was applied by judging on three domains with eight items:

1. Selection of study groups:

a) Representativeness of the average community-dwelling resident with uncontrolled NVUGIB who had TAE as rescue therapy

b) Selection of patients with uncontrolled NVUGIB who had surgery as rescue therapy

c) Ascertainment of the use of TAE or surgery as rescue therapy

d) Demonstration that bleeding was secured by either form of rescue therapy
2. Comparability of patients: comparability of patients on the basis of the study design or analysis.

3. Outcome of interest (rebleeding rate, mortality, additional intervention):

a) Assessment of rebleeding rate, mortality, additional intervention

b) Was followed up long enough (30 days)

c) Adequacy of follow-up of the patients; this refers to loss to follow up (less than $10 \%$ and reported) in Table 2

A star system is used to assess the quality of the study with a total score ranging from zero to nine stars. The maximum number of stars a study may receive in each of these 3 categories is 4, 2 and 3 , respectively. A study can be considered to have a low risk of bias if it was allocated the maximum number of stars. Studies with a score of 7 stars or greater were considered to be of high quality, and studies with a score of 3 stars or lower were deemed to be of low quality.

\section{Statistical analysis}

Relative risks (RRs) with corresponding 95\% confidence interval (95\%CI) were used to compare the outcomes between TAE and surgical groups. A meta-analysis using the Mantel-Haenszel method was performed to combine the results from different trials. A random-effects model [9], was used to take into account the possible clinical diversity and methodological variation among studies. The Cochrane $Q$ (chi- squared) test was used to test whether observed differences in results were compatible with chance alone and $P<0.1$ was considered to show significant heterogeneity. The impact of statistical heterogeneity was assessed using $I^{2}$ [10], which indicated the percentage of total variation across studies caused by heterogeneity. $I^{2}$ of more than $50 \%$ was considered substantial heterogeneity.

A sensitivity analysis was conducted based on quality assessment of studies. Publication bias was explored through visual inspection of the funnel plots and formally using Egger's regression asymmetry test [11]. Statistical analyses were performed using Intercooled STATA version 8 (Stata Corp, College Station, TX, USA) and RevMan software (Review Manager version 5.2; The Nordic Cochrane Centre, Copenhagen, Demark, The Cochrane Collaboration 2012) [12].

\section{Results \\ $\nabla$}

A total of 1234 abstracts were identified in the initial search. The majority of abstracts were excluded, as they were not relevant to the comparison between TAE and surgery. Of the 93 abstracts accepted, a further 87 were excluded for the following reasons: they related to use of TAE on lower gastrointestinal bleeding or on tumor-related gastrointestinal bleeding, they were review articles, or they were not comparative studies with surgery. The final analysis included 6 nonrandomized studies published between 2004 and 2012 ( $\bullet$ Fig. 1). All 6 studies were retrospective comparative studies. Up to the current date, no randomized controlled trials exist that compare TAE and surgery for control of NVUGIB following unsuccessful endoscopic hemostasis. One study included diverticular bleeding from the upper gastrointestinal tract [13]; the corresponding author was contacted to provide amended data with exclusion of the patients with diverticular upper gastrointestinal bleeding. 




Fig. 1 Meta-analysis of transcatheter arterial embolization (TAE) versus surgery for peptic ulcer bleeding after failed endoscopic hemostasis: literature search. Gl, gastrointestinal.

\section{Patients}

There were two studies from Asian populations and four studies from European populations. All 6 studies were published as full papers. A total of 423 patients were included in the analysis, of whom 182 patients underwent TAE (56\% male) and 241 patients received surgery (68\% male). The TAE cohort was older with a mean age of 75 years, compared with the surgical cohort, with a mean age of 68 years. Four studies used the Acute Physiology and Chronic Health Evaluation (APACHE) II score or American Society of Anesthesiologists (ASA) grades, or number of co-morbidities to evaluate the general condition of the patient and risk before TAE or surgery [13-16 ]. All 4 studies reported the TAE cohort to have patients with higher procedure-related risks ( $\bullet$ Table 1$)$.

Further risk factors for rebleeding, and mortality include duration of hospital stay prior to the first appearance of upper gastro- intestinal bleeding [2]. This was reported only in one study, with a significantly longer duration of hospital stay in TAE-treated patients compared with surgery [13]. The use of anticoagulation or aspirin or nonsteroidal anti-inflammatory drugs (NSAIDs) was reported in a majority of the studies with no significant differences between the TAE group and surgical group. However the reporting was only in the preoperative setting and no comments were made on the continuation of the drugs after TAE or surgery. No studies reported the use of proton pump inhibitors (PPIs) after TAE or surgery.

Four out of the six studies included both duodenal and gastric ulcers as bleeding sources, and two studies included only patients with duodenal ulcers as the sources of bleeding. Only one study reported the use of routine follow-up endoscopy after 24 hours but performed only in high risk patients; the number of patients who had follow-up routine endoscopy was not reported [13].

\section{TAE techniques}

The mechanism of embolotherapy and the description of different embolic agents for TAE was reported in only three studies $[13,15,17]$. Types of embolization agents used included coils, and particles (gelatin sponge [Gelfoam], or nonresorbable polyvinyl alcohol [PVA]). The main advantage of gelatin sponge was that it is adsorbable, and flow can be restored after embolization.

There was a variation in the use of different embolic agents: coils only $(11 \%$ to $89 \%)[13,15,17]$, particles $(18 \%$ to $42 \%)[13,15]$, combination of coils and particles ( $11 \%$ to $47 \%$ ) [13,17]. Localization of contrast extravasation into the bowel lumen was considered to be a direct angiographic sign of active gastrointestinal bleeding. If no evidence of bleeding was found on the pre-embolization arteriogram, then blind embolization was performed, typically guided by the endoscopic findings regarding the bleeding site. Such empirical embolization was performed in the majority of the studies ( 5 studies, 349 patients) [13,14,16-18]. The use of the "sandwich" technique was reported in only one study [13]. This technique involves embolization of the GDA (gastroduodenal artery) with both ends of the artery being filled with coils, with particles between the coils, to avoid retrograde bleeding from the superior mesenteric circulation.

Table 1 Patient baseline characteristics in studies comparing transcatheter arterial embolization (TAE) with surgery for nonvariceal upper gastrointestinal bleeding after failed endoscopic hemostasis.

\begin{tabular}{|c|c|c|c|c|c|c|c|c|c|c|c|c|c|c|}
\hline \multirow[t]{2}{*}{ Study } & \multirow[t]{2}{*}{$\begin{array}{l}\text { n } \\
\text { (TAE vs. } \\
\text { surgery) }\end{array}$} & \multicolumn{2}{|c|}{$\begin{array}{l}\text { Age, mean, } \\
\text { years }\end{array}$} & \multicolumn{2}{|c|}{$\begin{array}{l}\text { Gender, } \\
\text { male, \% }\end{array}$} & \multicolumn{2}{|c|}{$\begin{array}{l}\text { APACHE } \\
\text { score, } \\
\text { mean }\end{array}$} & \multicolumn{2}{|c|}{$\begin{array}{l}\text { ASA grades } \\
\text { ASA 1\&2: } \\
3 \& 4\end{array}$} & \multicolumn{2}{|c|}{$\begin{array}{l}\text { More than } \\
\text { one co-mor- } \\
\text { bidity, \% }\end{array}$} & \multicolumn{2}{|c|}{$\begin{array}{l}\text { NSAID or } \\
\text { aspirin, \% }\end{array}$} & \multirow[t]{2}{*}{$\begin{array}{l}\text { Bleeding } \\
\text { source, ulcer } \\
\text { type }\end{array}$} \\
\hline & & TAE & Surg & TAE & Surg & TAE & Surg & TAE & Surg & TAE & Surg & TAE & Surg & \\
\hline Ang 2012 [13] & $\begin{array}{l}54 \\
\text { (19 vs. } 35)\end{array}$ & 71 & 70 & 74 & 60 & n.a. & n.a. & $5: 14$ & $\begin{array}{l}22: 1- \\
3\end{array}$ & 68 & 46 & 21 & 11 & Gastroduodenal \\
\hline $\begin{array}{l}\text { Venclauskas } 2010 \\
\text { [15] }\end{array}$ & $\begin{array}{l}74 \\
\text { (24 vs. } 50)\end{array}$ & 70 & 72 & 54 & 76 & 17.0 & 12.8 & n.a. & n.a. & 75 & 40 & n.a. & n.a. & Duodenal \\
\hline Wong 2011 [14] & $\begin{array}{l}88 \\
(32 \text { vs. } 56)\end{array}$ & 73 & 71 & 66 & 71 & n.a. & n.a. & $\begin{array}{l}19: 1- \\
3\end{array}$ & $\begin{array}{l}30: 2- \\
6\end{array}$ & 87.5 & 87.5 & 25 & 17.9 & Gastroduodenal \\
\hline Larssen 2008 [17] & $\begin{array}{l}46 \\
(36 \text { vs. } 10)\end{array}$ & 80 & 72 & 47 & 60 & n.a. & n.a. & n.a. & n.a. & n.a. & n.a. & 31 & 40 & Duodenal \\
\hline Erikson 2008 [18] & $\begin{array}{l}91 \\
(40 \text { vs. } 51)\end{array}$ & 76 & 71 & 45 & 63 & n.a. & n.a. & n.a. & n.a. & n.a. & n.a. & n.a. & n.a. & Gastroduodenal \\
\hline Ripoll 2004 [16] & $\begin{array}{l}70 \\
\text { (31 vs. } 39)\end{array}$ & 75 & 63 & 61 & 74 & n.a. & n.a. & n.a. & n.a. & 90.3 & 79.5 & 38.7 & 35.9 & Gastroduodenal \\
\hline
\end{tabular}

APACHE, Acute Physiology and Chronic Health Evaluation; ASA, American Society of Anesthesiologists; NSAID, nonsteroidal anti-inflammatory drug; surg, surgery;

n.a., not available.

${ }^{1}$ Data updated directly from study principal investigators. 


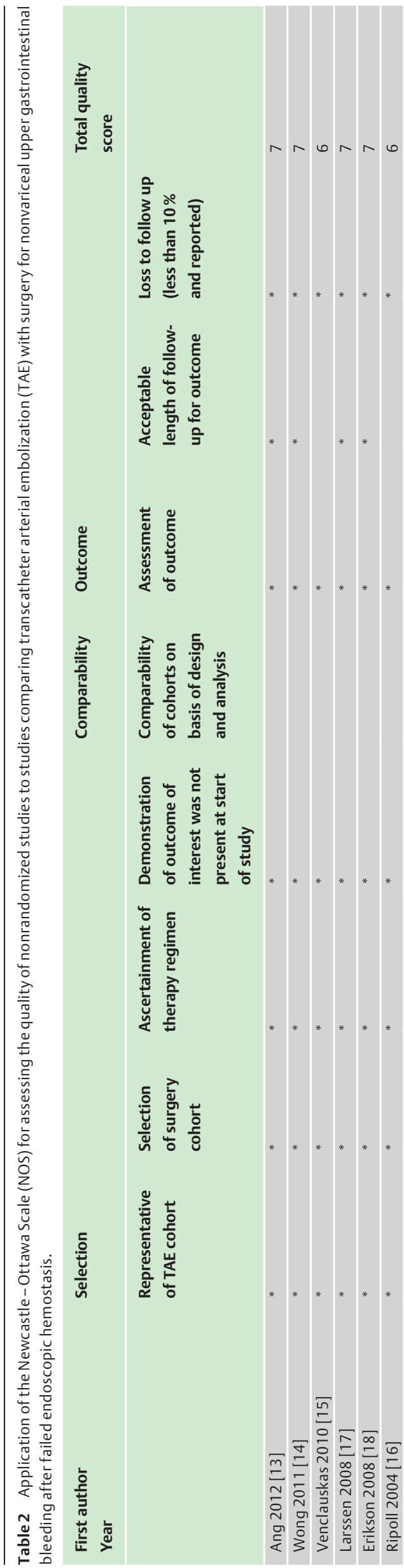

Two studies provided the proportion of patients where active extravasation was seen during angiography (33\% to $42 \%, 2$ studies, 100 patients) $[13,17]$. Two studies reported the sources of bleeding during angiography, with the majority coming from the gastroduodenal artery (78\% to $82 \%, 2$ studies, 179 patients) [14,18]. The second most common source of bleeding was the left gastric artery (13\%, 2 studies, 179 patients) $[14,18]$.

\section{Surgical techniques}

The types of rescue surgery after endoscopic failure were reported in five studies $[13-15,17,18]$. There was a variation in the surgical techniques used in the studies, with duodenectomy and oversewing (range $27 \%-68 \%, 5$ studies, 202 patients), and gastrectomy and reconstruction for drainage using Billroth I or Billroth II procedures (range 20\%-70\%, 5 studies, 202 patients), with Billroth II predominating ( Table 3 ). The use of vagotomy with a drainage procedure (gastrojejunostomy or pyloroplasty) was reported in only one study [14].

\section{Rebleeding and mortality}

All six studies reported the rebleeding rate ( $\bullet$ Table 4$)$. For the definition of rebleeding, although most studies reported the use of clinical signs (systolic blood pressure $\leq 90 \mathrm{mmHg}$ or pulse $\geq$ $110 / \mathrm{min}$, decrease in hemoglobin $>2 \mathrm{~g} / \mathrm{L}$ ), no description of endoscopic findings was added to the definition. Pooling the data from the studies ( 6 studies, 423 patients) showed that the rebleeding rate was higher in patients who received TAE compared with those treated surgically (RR $1.82,95 \% \mathrm{CI} 1.23-2.67$ ) [13-18]. No statistical heterogeneity was found among these studies $(P=0.66$, $\left.I^{2}=0.0 \%\right)(\bullet$ Fig. 2$)$.

The 30-day all-cause mortality was used as a definition for mortality $[13,14,17,18]$. Two studies did not report a time frame for the description of mortality $[15,16]$. Pooled data from the six studies (423 patients) showed that there was no significant difference in mortality rate following TAE, compared with surgery (RR 0.87, 95\%CI 0.591.29) [13-18]. No statistically significant heterogeneity was found among the studies $\left(P=0.67, I^{2}=0.0 \%\right)$ (๑ Fig.3).

\section{Additional interventions}

Five studies were identified for the comparison of need for additional intervention to secure hemostasis (377 patients) [13-16, 18]. Additional intervention included either a repeat endoscopy, $\mathrm{TAE}$, or surgery. The Cochrane $Q$ (chi-squared) test for heterogeneity produced a $P$ value of 0.08 . $I^{2}$ was $52.9 \%$, suggesting moderate heterogeneity. The random-effects model showed no statistically significant difference in requirement for additional intervention in the TAE group compared with surgery (RR 1.67, 95\% CI $0.75-3.70)(\diamond$ Fig. 4).

\section{Complications \\ TAE-related}

The studies showed a high initial technical success rate of TAE ( $90 \%$ to $100 \%, 5$ studies, 142 patients) [ $13-17]$. This is similar to the data from reported case series, where success rates were $92 \%$ to $98 \%$ [19-25]. Descriptions of technical failure of TAE varied from failure to access the bleeding vessel to continuing bleeding despite application of embolotherapy to the bleeding vessel. Three studies gave the definition of successful TAE as no contrast media extravasation shown at follow-up arteriography $[13,17$, 18]. The pooled frequency of TAE-related complications was low (4\%, 5 studies, $7 / 158$ patients) $[13,14,16-18]$, and complications 


\begin{tabular}{|c|c|c|c|c|c|c|c|c|c|c|}
\hline \multirow{2}{*}{$\begin{array}{l}\text { Study or Subgroup } \\
\text { Ripoll } 2004\end{array}$} & \multirow{2}{*}{$\begin{array}{r}\text { TAE } \\
\text { Events } \\
9\end{array}$} & \multirow{2}{*}{$\begin{array}{r}\text { Total } \\
31\end{array}$} & \multicolumn{2}{|c|}{ Surgery } & Weight & \multirow{2}{*}{$\begin{array}{c}\begin{array}{c}\text { Risk Ratio } \\
\text { M-H, Random, 95\% CI }\end{array} \\
1.26[0.57,2.78]\end{array}$} & Year & \multicolumn{3}{|c|}{$\begin{array}{c}\text { Risk Ratio } \\
\text { M-H, Random, } 95 \% \mathrm{Cl}\end{array}$} \\
\hline & & & 9 & 39 & $23.7 \%$ & & 2004 & & & $=$ \\
\hline Larssen 2008 & 10 & 36 & 2 & 10 & $8.2 \%$ & $1.39[0.36,5.34]$ & 2008 & & & 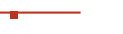 \\
\hline Eriksson 2008 & 10 & 40 & 9 & 51 & $23.4 \%$ & $1.42[0.64,3.15]$ & 2008 & & - & - \\
\hline Venclauskas 2010 & 3 & 20 & 4 & 50 & $7.6 \%$ & $1.88[0.46,7.64]$ & 2010 & & - & \\
\hline Wong 2011 & 11 & 32 & 7 & 56 & $21.1 \%$ & $2.75[1.18,6.38]$ & 2011 & & & $\longrightarrow$ \\
\hline Ang 2012 & 8 & 19 & 5 & 35 & $16.0 \%$ & $2.95[1.12,7.76]$ & 2012 & & & $\longrightarrow$ \\
\hline Total (95 \% Cl) & & 178 & & 241 & $100.0 \%$ & $1.82[1.23,2.67]$ & & & & \\
\hline Total events & 51 & & 36 & & & & & & & \\
\hline \multicolumn{7}{|c|}{ Heterogeneity: Tau $^{2}=0.00 ; \mathrm{Chi}^{2}=3.24, \mathrm{df}=5(\mathrm{P}=0.66) ; \mathrm{I}^{2}=0 \%$} & & 0.01 & $\begin{array}{cc}1 & 1 \\
0.1 & 1\end{array}$ & 10 \\
\hline
\end{tabular}

Fig. 2 Rebleeding after transcatheter arterial embolization (TAE) versus surgery for peptic ulcer bleeding after failed endoscopic hemostasis: forest plot. Cl, confidence interval.



Fig. 3 Mortality after transcatheter arterial embolization (TAE) versus surgery for peptic ulcer bleeding after failed endoscopic hemostasis: forest plot. Cl, confidence interval.



Fig. 4 Need for additional intervention after transcatheter arterial embolization (TAE) versus surgery for peptic ulcer bleeding after failed endoscopic hemostasis: forest plot. $\mathrm{Cl}$, confidence interval.

included: ischemic pancreatitis (1 patient)[13], renal impairment (3 patients) [14], and misplacement of coils (3 patients) [17].

\section{Surgery-related}

There was a variation in the descriptions of surgery-related complication amongst the studies. The pooled frequency of surgeryrelated complications was high (46\%, 5 studies, 94/202 patients) $[13-15,17,18]$. Only 3 studies (117 patients) provided the frequency of various types of complications, which included: pneumonia (24 patients); postoperative abscess ( 3 patients); duodenal stump leakage (10 patients); stroke (5 patients); atrial fibrillation ( 2 patients); myocardial infarction ( 5 patients); cardiopul- monary insufficiency ( 2 patients); renal failure ( 8 patients); multiorgan failure (3 patients); other (19 patients) [14,17,18].

\section{Sensitivity analysis and publication bias}

A post hoc sensitivity analysis was conducted to investigate whether age was a possible confounding factor. After exclusion of those studies that had a large difference in mean age between their TAE group and their surgery group (Larssen et al., Eriksson et al., and Ripoll et al.) [16-18], the pooled rebleeding rate increased in the TAE group ( $R R 2.64,95 \% \mathrm{CI} 1.48-4.71$ ), while the mortality rate decreased (RR 0.84, 95\%CI 0.521 .35 ). 
Table 3 Surgical techniques and transcatheter arterial embolization (TAE) techniques.

\begin{tabular}{|c|c|c|c|c|c|c|}
\hline & $\begin{array}{l}\text { Ang } 2012 \text { [13] } \\
\%(n)\end{array}$ & $\begin{array}{l}\text { Wong } 2011[14] \\
\%(n)\end{array}$ & $\begin{array}{l}\text { Venclauskas } 2010 \\
\text { [15] \% (n) }\end{array}$ & $\begin{array}{l}\text { Larssen } 2008 \text { [17] } \\
\% \text { (n) }\end{array}$ & $\begin{array}{l}\text { Erikson } 2008 \text { [18] } \\
\% \text { (n) }\end{array}$ & $\begin{array}{l}\text { Ripoll } 2004 \\
{[16] \% \text { (n) }}\end{array}$ \\
\hline \multicolumn{7}{|l|}{ Surgical techniques } \\
\hline $\begin{array}{l}\text { Duodenectomy and } \\
\text { over-sewing }\end{array}$ & $\begin{array}{l}49 \\
(17 / 35)\end{array}$ & $\begin{array}{l}68 \\
(38 / 56)\end{array}$ & $\begin{array}{l}36 \\
(18 / 50)\end{array}$ & $\begin{array}{l}30 \\
(3 / 10)\end{array}$ & $\begin{array}{l}27 \\
(14 / 51)\end{array}$ & n.a. \\
\hline $\begin{array}{l}\text { Gastrectomy }{ }^{+} \\
\text {reconstruction }{ }^{1}\end{array}$ & $\begin{array}{l}51 \\
(18 / 35)\end{array}$ & $\begin{array}{l}20 \\
(11 / 56)\end{array}$ & $\begin{array}{l}64 \\
(32 / 50)\end{array}$ & $\begin{array}{l}70 \\
(7 / 10)\end{array}$ & $\begin{array}{l}57 \\
(29 / 51)\end{array}$ & n.a. \\
\hline Billroth I & $\begin{array}{l}3 \\
(1 / 35)\end{array}$ & 0 & $\begin{array}{l}28 \\
(14 / 50)\end{array}$ & 0 & 0 & \\
\hline Billroth II & $\begin{array}{l}49 \\
(17 / 35)\end{array}$ & $\begin{array}{l}20 \\
(11 / 56)\end{array}$ & $\begin{array}{l}36 \\
(18 / 50)\end{array}$ & $\begin{array}{l}70 \\
(7 / 10)\end{array}$ & $\begin{array}{l}57 \\
(29 / 51)\end{array}$ & \\
\hline $\begin{array}{l}\text { Vagotomy+ } \\
\text { drainage }^{2}\end{array}$ & & $\begin{array}{l}13 \\
(7 / 56)\end{array}$ & & & & \\
\hline Re-resection after Billroth & & & & & $\begin{array}{l}12 \\
(6 / 51)\end{array}$ & \\
\hline Other ${ }^{3}$ & & & & & $\begin{array}{l}4 \\
(2 / 51)\end{array}$ & \\
\hline \multicolumn{7}{|l|}{ TAE techniques } \\
\hline Gelfoam & $\begin{array}{l}42 \\
(8 / 19)\end{array}$ & & n.a. & & & n.a. \\
\hline Coil & $\begin{array}{l}11 \\
(2 / 19)\end{array}$ & $\begin{array}{l}60 \\
(12 / 20)\end{array}$ & n.a. & $\begin{array}{l}89 \\
(32 / 36)\end{array}$ & & n.a. \\
\hline Gelfoam + coil & $\begin{array}{l}47 \\
(9 / 19)\end{array}$ & & n.a. & $\begin{array}{l}11 \\
(4 / 36)\end{array}$ & & n.a. \\
\hline Glue & & $\begin{array}{l}10 \\
(2 / 20)\end{array}$ & n.a. & & & n.a. \\
\hline $\begin{array}{l}\text { Polyvinyl alcohol (PVA) } \\
\text { particles }\end{array}$ & & $\begin{array}{l}30 \\
(6 / 20)\end{array}$ & n.a. & & & n.a. \\
\hline $\begin{array}{l}\text { Blind/empiric } \\
\text { embolization }\end{array}$ & Yes & Yes & No & Yes & Yes & Yes \\
\hline
\end{tabular}

n.a., not available.

${ }^{1}$ Gastrectomy with reconstruction with either Billroth I or Billroth II procedure.

2 Vagotomy and drainage procedure, gastrojejunostomy or pyloroplasty.

${ }^{3}$ Explorative laparotomy and small-intestine resection.

\begin{tabular}{|c|c|c|c|c|c|c|c|}
\hline \multirow[t]{2}{*}{ Study } & \multirow[t]{2}{*}{ Patients, n } & \multicolumn{2}{|c|}{ Rebleeding \% ( $n$ ) } & \multicolumn{2}{|c|}{ Mortality \% (n) } & \multicolumn{2}{|c|}{ Additional intervention \% (n) } \\
\hline & & TAE & Surg & TAE & Surg & TAE & Surg \\
\hline Ang 2012 [13] & 54 & $\begin{array}{l}42 \\
(8 / 19)\end{array}$ & $\begin{array}{l}14 \\
(5 / 35)\end{array}$ & $\begin{array}{l}26 \\
(5 / 19)\end{array}$ & $\begin{array}{l}34 \\
(12 / 35)\end{array}$ & $\begin{array}{l}32 \\
(6 / 19)\end{array}$ & $\begin{array}{l}9 \\
(3 / 35)\end{array}$ \\
\hline Wong 2011 [14] & 88 & $\begin{array}{l}34 \\
(11 / 32)\end{array}$ & $\begin{array}{l}13 \\
(7 / 56)\end{array}$ & $\begin{array}{l}25 \\
(8 / 32)\end{array}$ & $\begin{array}{l}30 \\
(17 / 56)\end{array}$ & $\begin{array}{l}25 \\
(8 / 32)\end{array}$ & $\begin{array}{l}9 \\
(5 / 56)\end{array}$ \\
\hline Venclauskas 2010 [15] & 74 & $\begin{array}{l}15 \\
(3 / 20)^{1}\end{array}$ & $\begin{array}{l}8 \\
(4 / 50)\end{array}$ & $\begin{array}{l}21 \\
(5 / 24)\end{array}$ & $\begin{array}{l}22 \\
(11 / 50)\end{array}$ & $\begin{array}{l}8 \\
(2 / 24)\end{array}$ & $\begin{array}{l}6 \\
(3 / 50)\end{array}$ \\
\hline Larssen 2008 [17] & 46 & $\begin{array}{l}28 \\
(10 / 36)\end{array}$ & $\begin{array}{l}20 \\
(2 / 10)\end{array}$ & $\begin{array}{l}19 \\
(7 / 36)\end{array}$ & $\begin{array}{l}20 \\
(2 / 10)\end{array}$ & n.a. & n.a. \\
\hline Erikson 2008 [18] & 91 & $\begin{array}{l}25 \\
(10 / 40)\end{array}$ & $\begin{array}{l}18 \\
(9 / 51)\end{array}$ & $\begin{array}{l}3 \\
(1 / 40)\end{array}$ & $\begin{array}{l}14 \\
(7 / 51)\end{array}$ & $\begin{array}{l}13 \\
(5 / 40)\end{array}$ & $\begin{array}{l}6 \\
(3 / 51)\end{array}$ \\
\hline Ripoll 2004 [16] & 70 & $\begin{array}{l}29 \\
(9 / 31)\end{array}$ & $\begin{array}{l}23 \\
(9 / 39)\end{array}$ & $\begin{array}{l}26 \\
(8 / 31)\end{array}$ & $\begin{array}{l}21 \\
(8 / 39)\end{array}$ & $\begin{array}{l}16 \\
(5 / 31)\end{array}$ & $\begin{array}{l}31 \\
(12 / 39)\end{array}$ \\
\hline
\end{tabular}

surg, surgery; n.a., not available.

1 Total number of patients, in cases with missing data.

A post hoc sensitivity analysis was also performed to investigate co-morbidities as confounding factor. After exclusion of those studies where there was a large difference between the TAE group and the surgery group in the percentage of patients with more than one co-morbidity (Ang et al. and Venclauskas et al. $[13,15]$; also Larssen et al. and Eriksson et al. [17,18], because information was unavailable) the pooled rebleeding risk remained higher for the TAE group (RR 1.84, 95\%CI 0.85-3.95), and there was no difference in mortality rate (RR $0.87,95 \% \mathrm{CI} 0.59-1.29$ ). A sensitivity analysis using a random-effects model was performed with exclusion of one study that did not use empiric embolization. There was still a significantly higher risk of rebleeding in patients who received TAE compared with those treated surgically (RR $1.81,95 \%$ CI $1.21-2.71, P=0.004$ ), but no difference in 
mortality (RR $0.86,95 \% \mathrm{CI} 0.56-1.32, P=0.48$ ), or in requirement for additional intervention (RR 1.74, 95\%CI 0.67-4.52, $P=0.25$ ).

The tests for funnel plot asymmetry (Egger's test) showed a low probability of publication bias (rebleeding, $P=0.86$; mortality, $P$ $=0.19$; additional intervention, $P=0.48$ ).

The Newcastle-Ottawa Scale (NOS) for assessing the quality of nonrandomized studies is shown in $\bullet$ Table 2 and the scores ranged from 6 to 7. Four studies had a score of 7 stars and were considered to be of high quality. Two studies with moderate risk of bias had unclear definition of the follow-up period for mortality. A sensitivity analysis based on the quality assessment of studies was conducted to test robustness of the results [8]. In these studies comparing TAE with surgery it was found that studies with higher quality (NOS score $\geq 7$ ) would still demonstrate a significantly increased risk of rebleeding in the TAE-treated patients (RR 2.05, 95\%CI 1.29-3.28), but no difference in mortality (RR $0.75,95 \% \mathrm{CI} 0.45-1.24)$. As only five studies provided data on the requirement for an additional intervention, no sensitivity analysis on quality assessment of studies was conducted for this secondary outcome.

\section{Discussion}

$\nabla$

The management of patients with NVUGIB not controlled by endoscopy remains a challenge, and the decision to choose TAE or surgery remains solely at the discretion of the attending clinician. This meta-analysis was performed to summarize the current evidence available, and help such clinicians in the choice of salvage therapy.

This paper has several limitations. Although numerous case studies exist on the use of TAE to treat NVUGIB, there are few published articles that compare TAE with surgery. To date there are no prospective data comparing the role of TAE and surgery as a salvage therapy for patients with NVUGIB. After exclusion of any studies that did not compare TAE with surgery, only 6 studies were eligible for the meta-analysis. These studies are all retrospective observational comparative studies. The main problem with such observational studies was patient selection bias. TAE was considered to be a safer approach than surgery, which would have led to selection bias, as patients with higher surgical risk factor would be offered TAE. It has already been suggested that old age, and multiple co-morbidities are associated with rebleeding and mortality [26, 27]. Thus, there is a tendency for older patients and those with multiple co-morbidities to be offered TAE instead of surgery. Alternatively, it would have been unlikely that an unstable patient with severe bleeding peptic ulcer would have been transferred to a radiology suite rather than having surgery. Conventional statistical approaches used in observational analyses have limited ability to address the influence of unmeasured confounders on the overall effect estimate.

There was inconsistency in the definitions of patient demographic data and clinical outcomes. There was variation across the studies in the definition of rebleeding; a standardized description of rebleeding using both clinical signs and endoscopic features may be of benefit. A range of scores was used to describe the patients' pre-morbid conditions prior to TAE or surgery; this included APACHE II score, ASA grades, and percentage of patients with co-morbidities. Because of the small number of studies and difficulty in extrapolating the data from the original studies, it was not possible to conduct a meta-regression to compare poor health status of patients with outcomes after TAE or surgery.
To our knowledge, this is the first meta-analysis that has compared TAE with surgery in the treatment of patients with recurrent NVUGIB in whom endoscopic hemostasis had failed. Our meta-analysis included 6 retrospective comparative studies published between 2004 and 2013, and involving 423 patients in the primary analysis of clinically important rebleeding and mortality. Compared with surgery, there were significantly more episodes of rebleeding in patients who received TAE (RR 1.82, 95\%CI $1.23-2.67)$. However, despite the higher rebleeding rate in the TAE-treated cohort, we found no significant differences in 30day mortality when compared with patients who underwent surgery. In fact the mortality rate was lower in the TAE-treated patients (RR 0.87) but the 95\% confidence interval did not show any significance differences (95\%CI 0.59-1.29).

Because of the variation in the reporting of patients' physical status it was difficult to quantify a cumulative procedure-related risk, but all studies reported the TAE cohort of patients to be the highest risk group, with a higher mean age (75 versus 68 years). Despite the evidence of higher prevalence of risk factors for poor outcome in the TAE- treated group, there was no difference in the more definitive clinical outcomes such as mortality or the need for additional intervention to secure hemostasis (RR 1.67, 95\%CI $0.75-3.70$ ). With inadequate data from the original studies, we were not able to compare mortality using a subgroup analysis by high risk status. However, a subgroup analysis done by Venclauskas et al. showed that there was no difference in mortality between the groups if the APACHE II score was less than 16.5, but mortality doubled in the surgical group if the score was greater than 16.5 [15].

Different strategies for embolization can be classified into localized, proximal, and segmental embolization and the choice of technique depends on the vascular anatomy, angiographic findings, the achievable catheter position, and operator preference [28]. The high rebleeding rate in some studies may be explained by the complexity of the anatomy of the gastroduodenal artery. The gastroduodenal artery has a dual supply from both the hepatic artery and the superior mesenteric artery resulting in the confluence of gastroduodenal, transverse pancreatic, superior pancreaticoduodenal, and right gastroepiploic arteries. Coiling the gastroduodenal artery solely from the celiac axis may result in back pressure in the superior mesenteric artery with continuing bleeding or risk of recurrent bleeding. Thus, the "sandwich technique" has been developed in which both ends of the artery (proximal and distal to the bleeding site) are filled with coils to avoid retrograde bleeding from the superior mesenteric circulation [29].

There is still controversy over the influence of the type of embolic agent used during TAE. The choice varies between metallic coil, gelatin sponge, polyvinyl alcohol (PVA) particles, or cyanoacrylate glue $[30,31]$; and whether to use single or dual agents remains a matter of debate. It has been suggested that the form of embolic agent does not seem to affect clinical response, but combination of two agents may be more effective [27,32]. Aina et al compared embolization with coils alone versus coils combined with particles; the use of coils alone was associated with higher re-bleeding [33]. Blind embolization without the angiographic proof of extravasation also remains controversial. Massive bleeding can be intermittent and active extravasation of contrast may not be seen in these patients with compromised hemodynamic circulation. Such theoretical concerns have led to increased usage of empirical embolization [34]. 
What is the explanation for the higher bleeding rate in TAE-treated patients compared with those who underwent surgery? The reason for the superior efficacy in securing hemostasis shown in the surgically treated cohort may be the variation in the embolization procedures within the studies; this is supported by the discrepancy in rebleeding rates reported in TAE cohorts (15\%$42.1 \%$ ). The differences included the use of different embolic agents for TAE (coils alone, particles alone, coils and particles in combination), techniques of embolization (blind embolization, and with or without sandwich technique). There was a high percentage use of blind or empirical embolization amongst the studies. This may be related to the low reported proportion of active extravasation seen during angiography (33\% to $42 \%, 2$ studies, 54 patients) $[13,17]$. Independent series published by Aina et al. [33], Loffroy et al. [27], and Padia et al. [35] have reported no difference in outcomes between patients who underwent blind embolization and those who underwent embolization after a bleeding site had been identified angiographically. Despite this, endoscopy remains a crucial procedure for selecting the target vessel for blind embolization, yet only 3 studies reported the placement of clips around the bleeding site during the pre-embolization endoscopy $[13,14,18]$. In addition, no studies reported visualization of clips as guidance during embolotherapy. The information available on the techniques was very limited and success depends highly on the technique. Empirical embolization is particularly susceptible to failure if the technique used is not optimal.

An additional explanation for higher bleeding rate after TAE may be the use of gelatin sponge. The main advantage of gelatin sponge was that it is resorbable with flow being restored after embolization, but this may also aggravate rebleeding. Further predisposition to rebleeding may be caused by a too central position of the coil in the vascular bed, allowing sufficient opportunity for the collateral circulation to supply the bleeding site. The use of the "sandwich technique" to prevent bleeding from collateral vessels was reported in only one study. Thus, it is likely that the techniques used in the studies were not optimal and this may be the main explanation for a higher rebleeding rate after TAE. Only three studies reported the techniques of TAE used with the choice of embolic agents, with only one study providing images of the technique. With these limited data it was not possible to find any significant relation between the frequency of rebleeding and embolization techniques and agents. From the three most recent studies that have reported the techniques of TAE, these techniques have not changed over the years $[13,15,17]$. This suggests that further focus is needed on improving techniques, as in the recent reports of the use of cyanoacrylate glue that have shown promising results $[30,31]$.

In our meta-analysis, with active bleeding seen during angiography in a low proportion of patients, empirical embolization was used in most of the studies (5 studies, 158 patients) [13,14,1618]. Complications including ischemia after TAE have been reported, hence the decision to use embolization despite the absence of angiographic evidence is controversial [34]. In our metaanalysis, the rate of TAE-related complications was low, (4\%, 5 studies, $7 / 158$ patients) $[13,14,16-18]$, with only one patient developing ischemia [13]. Other reported complications include renal impairment (3 patients) [14] and misplacement of coils (3 patients) [17]. When empirical embolization is considered, such risks have to be weighed with the risks of further bleeding. In comparison, surgery-related complications were much higher at $46 \%$ (5 studies, $94 / 202$ patients) [13-15,17,18].
Post hoc sensitivity analysis was carried out to investigate whether age was a possible confounding factor. After a pooled analysis with exclusion of those studies that had large differences in age between the TAE and the surgery groups (Larssen et al., Eriksson et al., and Ripoll et al.) [16-18], the rebleeding rate increased in the TAE group (RR 2.64, 95\% CI 1.48-4.71), and mortality rate decreased (RR $0.84,95 \% \mathrm{Cl} 0.52-1.35)$. This may imply that the higher rebleeding rate seen in the TAE group may not be due to older age. It was not possible to conduct a subgroup analysis for age as a covariate because of the limited mean age range of the surgical subgroups in these elderly patients (see $\bullet$ Table 1 ). If two subgroups had been defined at mean age $<70$ years versus mean age $\geq 70$ years, only one study (Ripoll et al. [16]) would have contributed a $<70$ years surgical subgroup. However, with a higher age cutoff at mean $<75$ years versus mean $\geq 75$ years, none of the studies could have provided $a \geq 75$ years surgical subgroup.

To investigate co-morbidities as confounding factor, a post hoc sensitivity analysis was performed after exclusion of those studies with a large difference between the TAE and surgery groups in the percentage of patients with more than one co-morbidity (Ang et al. and Venclauskas et al.; also Larssen et al. and Eriksson et al. because information was not available $[13,15,17,18])$. With only 2 studies included (Ripoll et al. and Wong et al.) [14,16], the pooled rebleeding risk remained higher for the TAE group (RR $1.84,95 \% \mathrm{Cl} 0.85-3.95)$ and there was no difference in mortality rate (RR $0.87,95 \%$ CI $0.59-1.29$ ). It was not possible to adjust for co-morbidity with subgroup analysis as only 4 out of the 6 studies reported co-morbidities, and in those 4 studies co-morbidities were described in three different ways: mean APACHE score, ASA grades, and percentage of patients with more than one comorbidity.

Although data from randomized controlled trials are usually preferred for meta-analysis, they are not always plausible, and only data from observational studies may be available [36]. Increasing numbers of meta-analyses are being published that use observational studies [37]. Compared with meta-analyses of randomized controlled trials, meta-analyses of observational studies present different challenges because of the inherent bias from the original studies and the variation in their study designs, yet it is important to analyze and quantify the variation across the existing studies [38]. A combined checklist produced by the PRISMA (Preferred Reporting Items for Systematic reviews and Meta-Analyses) group [39] and the MOOSE (Meta-analysis Of Observational Studies in Epidemiology) group [37] was used as a guideline in reporting this meta-analysis of observational studies.

\section{Conclusion}

In our meta-analysis, a higher rebleeding rate was seen in patients who were treated with embolization; however these patients were older and of poorer health status compared with those who underwent surgery. With current limited data from observational studies, it is difficult to conclude which procedure should be offered as the first-line intervention. Future randomized studies are needed for accurate comparison of the two modalities. Currently at our center, a randomized controlled trial comparing the two techniques is underway (ClinicalTrials.gov. study identifier: NCT007669616). Furthermore, for genuine randomization, and to prevent selection bias, angiographic facilities must be available to support patients in an unstable condition if randomization resulted in their allocation to TAE.

Competing interests: None 


\section{References}

1 Cook DJ, Guyatt GH, Salena BJ et al. Endoscopic therapy for acute nonvariceal upper gastrointestinal hemorrhage: a meta-analysis. Gastroenterology 1992; 102: 139-148

2 Rockall TA, Logan RF, Devlin HB. Steering Committee and members of the National Audit of Acute Upper Gastrointestinal Haemorrhage. et al. Incidence of and mortality from acute upper gastrointestinal haemorrhage in the United Kingdom. BMJ 1995; 311: 222 -226

3 de Manzoni G, Catalano F, Festini $M$ et al. Emorragia acuta da ulcera duodenale. Risultati del trattamento endoscopico del primo sanguinamento e delle recidive. (In Italian.) [Acute hemorrhage caused by duodenal ulcer. Results of endoscopic treatment of the first bleeding episode and of recurrences]. Ann Ital Chir 2002; 73: 387-394, discussion 394-396

4 Cheynel $N$, Peschaud $F$, Hagry $O$ et al. Ulcère gastroduodénal hémorragique: résultats du traitement chirurgical. (in French). [Bleeding gastroduodenal ulcer: results of surgical management]. Ann Chir 2001; 126: $232-235$

5 Lau JY, Sung JJ, Lam YH et al. Endoscopic retreatment compared with surgery in patients with recurrent bleeding after initial endoscopic control of bleeding ulcers. N Engl J Med 1999; 340: 751 - 756

6 Barkun AN, Bardou M, Kuipers EJ et al. International consensus recommendations on the management of patients with nonvariceal upper gastrointestinal bleeding. Ann Intern Med 2010; 152: 101 - 113

7 Rösch J, Dotter CT, Brown MJ. Selective arterial embolization. A new method for control of acute gastrointestinal bleeding. Radiology 1972; 102: $303-306$

8 Wells GA, Shea B, O'Connell D et al. The Newcastle-Ottawa Scale (NOS) for assessing the quality of nonrandomized studies in meta-analysis. 2011: Accessed September 2, 2013.

9 DerSimonian R, Laird N. Meta-analysis in clinical trials. Control Clin Trials 1986; 7: $177-188$

10 Higgins JP, Thompson SG. Quantifying heterogeneity in a meta-analysis. Stat Med 2002; 21: 1539-1558

11 Egger M, Davey Smith G, Schneider M et al. Bias in meta-analysis detected by a simple, graphical test. BMJ 1997; 315: 629-634

12 The Nordic Cochrane Centre. The Cochrane Collaboration Review Manager (RevMan) computer program, Version 5.0. 2012

13 Ang $D, T e o E K$, Tan $A$ et al. A comparison of surgery versus transcatheter angiographic embolization in the treatment of nonvariceal upper gastrointestinal bleeding uncontrolled by endoscopy. Eur J Gastroenterol Hepatol 2012; 24: 929-938

14 Wong TC, Wong KT, Chiu PW et al. A comparison of angiographic embolization with surgery after failed endoscopic hemostasis to bleeding peptic ulcers. Gastrointest Endosc 2011; 73: 900-908

15 Venclauskas L, Bratlie SO, Zachrisson $\mathrm{K}$ et al. Is transcatheter arterial embolization a safer alternative than surgery when endoscopic therapy fails in bleeding duodenal ulcer? Scand J Gastroenterol 2010; 45: $299-304$

16 Ripoll C, Bañares R, Beceiro I et al. Comparison of transcatheter arterial embolization and surgery for treatment of bleeding peptic ulcer after endoscopic treatment failure. J Vasc Interv Radiol 2004; 15: 447-450

17 Larssen L, Moger T, Bjørnbeth BA et al. Transcatheter arterial embolization in the management of bleeding duodenal ulcers: a 5.5-year retrospective study of treatment and outcome. Scand J Gastroenterol 2008; 43: $217-222$

18 Eriksson LG, Ljungdahl M, Sundbom $M$ et al. Transcatheter arterial embolization versus surgery in the treatment of upper gastrointestinal bleeding after therapeutic endoscopy failure. J Vasc Interv Radiol 2008; 19: $1413-1418$

19 Okazaki M, Higashihara H, Ono H et al. Embolotherapy of massive duodenal hemorrhage. Gastrointest Radiol 1992; 17: 319-323
20 Lang EK. Transcatheter embolization in management of hemorrhage from duodenal ulcer: long-term results and complications. Radiology 1992; 182: $703-707$

21 Toyoda H, Nakano S, Takeda I et al. Transcatheter arterial embolization for massive bleeding from duodenal ulcers not controlled by endoscopic hemostasis. Endoscopy 1995; 27: $304-307$

22 Walsh RM, Anain P, Geisinger $M$ et al. Role of angiography and embolization for massive gastroduodenal hemorrhage. J Gastrointest Surg 1999; 3: 61 -65, discussion 66

23 De Wispelaere JF, De Ronde T, Trigaux JP et al. Duodenal ulcer hemorrhage treated by embolization: results in 28 patients. Acta Gastroenterol Belg 2002; 65: 6-11

24 Ljungdahl M, Eriksson LG, Nyman R et al. Arterial embolisation in management of massive bleeding from gastric and duodenal ulcers. Eur J Surg 2002; 168: $384-390$

25 Holme JB, Nielsen DT, Funch-Jensen P et al. Transcatheter arterial embolization in patients with bleeding duodenal ulcer: an alternative to surgery. Acta Radiol 2006; 47: 244-247

26 Branicki FJ, Coleman SY, Fok PJ et al. Bleeding peptic ulcer: a prospective evaluation of risk factors for rebleeding and mortality. World J Surg 1990; 14: 02262 -269, discussion 269-270

27 Loffroy R, Guiu B, D'Athis $P$ et al. Arterial embolotherapy for endoscopically unmanageable acute gastroduodenal hemorrhage: predictors of early rebleeding. Clin Gastroenterol Hepatol 2009; 7: 515-523

28 Shin JH. Recent update of embolization of upper gastrointestinal tract bleeding. Korean J Radiol 2012; 13: 31 -S39

29 Loffroy R, Rao P, Ota $S$ et al. Embolization of acute nonvariceal upper gastrointestinal hemorrhage resistant to endoscopic treatment: results and predictors of recurrent bleeding. Cardiovasc Intervent Radiol 2010; 33: $1088-1100$

30 Mine T, Murata S, Nakazawa K et al. Glue embolization for gastroduodenal ulcer bleeding: contribution to hemodynamics and healing process. Acta Radiol 2013; 54: 934-938

31 Murata S, Onozawa S, Nakazawa K et al. Glue embolization for endoscopically unmanageable gastrointestinal haemorrhage. Hepatogastroenterology 2012; 59: 1126-1130

32 Loffroy R, Estivalet L, Cherblanc $V$ et al. Transcatheter embolization as the new reference standard for endoscopically unmanageable upper gastrointestinal bleeding. World J Gastrointest Surg 2012; 4: 223 -227

33 Aina R, Oliva VL, Therasse E et al. Arterial embolotherapy for upper gastrointestinal hemorrhage: outcome assessment. J Vasc Interv Radiol 2001; 12: 195-200

34 Poultsides GA, Kim CJ, Orlando RIII et al. Angiographic embolization for gastroduodenal hemorrhage: safety, efficacy, and predictors of outcome. Arch Surg 2008; 143: 457-461

35 Padia SA, Geisinger MA, Newman JS et al. Effectiveness of coil embolization in angiographically detectable versus non-detectable sources of upper gastrointestinal hemorrhage. J Vasc Interv Radiol 2009; 20: $461-466$

36 Berlin JA. Invited commentary: benefits of heterogeneity in meta-analysis of data from epidemiologic studies. Am J Epidemiol 1995; 142: $383-387$

37 Stroup DF, Berlin JA, Morton SC et al. Meta-analysis of observational studies in epidemiology: a proposal for reporting. Meta-analysis of Observational Studies in Epidemiology (MOOSE) group. JAMA 2000; 283: $2008-2012$

38 Egger M, Schneider M, Davey SmithG. Spurious precision? Meta-analysis of observational studies BMJ 1998; 316: 140 - 144

39 Moher D, Liberati A, Tetzlaff J et al. Preferred reporting items for systematic reviews and meta-analyses: the PRISMA statement. BM] 2009; 339: b2535 